\title{
Taxonomic Note: Necessary Correction of Specific Epithets Formed as Substantives (Nouns) "in Apposition"
}

\author{
HANS G. TRÜPER ${ }^{1 *}$ AND LANFRANCO DE' CLARI ${ }^{2}$ \\ Institut für Mikrobiologie \& Biotechnologie, Rheinische Friedrich-Wilhelms-Universität, D-53115 Bonn, Germany, ${ }^{1}$ \\ and Infectious Diseases Unit, Clinica al Parco, CH-6900 Lugano, Switzerland ${ }^{2}$
}

\begin{abstract}
Forming Latin species names (specific epithets) as "nominative nouns in apposition" (according to Rule 12c of the International Code of Nomenclature of Bacteria) has often been misunderstood or posed problems. Here, this grammatical construction is explained, and 24 cases that did not meet the requirements for this type of construction are corrected to a genitive noun or adjectival form in agreement with Rule 12c.
\end{abstract}

Rule $12 \mathrm{c}$ of the International Code of Nomenclature of Bacteria (3) states that a specific epithet must be treated in one of the three following ways: (i) as an adjective that must agree in gender with the generic name; (ii) as a substantive (noun) in apposition in the nominative case; or (iii) as a substantive (noun) in the genitive case. Correct examples of these three ways are Staphylococcus aureus (adjective: "golden"), Desulfovibrio gigas (nominative noun: "the giant"), and Escherichia coli (genitive noun: "of the colon"), respectively.

While the first and third ways are generally well-understood and usually do not pose problems, the formation of epithets as substantives in apposition has obviously been misunderstood in several cases. A nominative noun in apposition does not just mean that any nominative noun may be added to the generic name to automatically become its acceptable epithet. In grammar, apposition means "the placing of a word or expression beside another so that the second explains and has the same grammatical construction as the first" (2); i.e., the added nominative noun has an explanatory specifying function for the generic name, like in general English usage "the Conqueror" has for "William" in "William, (called) the Conqueror." Thus, Desulfovibrio gigas may be understood as Desulfovibrio dictus gigas and translated as "Desulfovibrio, called the giant," which-with reference to the unusual cell size of this speciesmakes sense.

Because all specific epithets ending with the Latin suffixes -cola (derived from incola, "the inhabitant, dweller") and -cida ("the killer") fulfill the above-mentioned requirement, they are to be considered correct. These constructions are, according to the newest compilation of validated procaryote names (1), Buchnera aphidicola, Carnobacterium piscicola, Chlorobium limicola, Desulfonema limicola, Melittangium lichenicola, Methanoplanus limicola, Roseburia cecicola, Roseobacter algicola, Salinivibrio (formerly Vibrio) costicola, Serratia fonticola, Xanthomonas arboricola, Xanthomonas theicola, and Xanthomonas vasicola, as well as Vibrio penaeicida and Vibrio salmonicida.

Furthermore, the following names are acceptable in this sense (explanations are in parentheses): Aquaspirillum anulus ("the ring," morphology), Aquaspirillum serpens ("the snake," morphology), Archangium gephyra ("the path, dam, bridge," typical growth forms), Coprococcus comes ("the consort"), Cupriavidus necator ("the killer," ecophysiology), Desulfovibrio gigas ("the giant," size), Eubacterium ramulus ("the twig," mor-

\footnotetext{
* Corresponding author. Mailing address: Institut für Mikrobiologie \& Biotechnologie, Rheinische Friedrich-Wilhelms-Universität, Meckenheimer Allee 168, D-53115 Bonn, Germany. Phone: 49228732320. Fax: 49228 737576. E-mail: trueper@uni-bonn.de.
}

phology), Labrys monachus ("the monk," in the sense of "the unique one," pertaining to morphology; a debatable case), Melittangium boletus ("the mushroom," pertaining to fruiting body formation), Obesumbacterium proteus ("the manifold," i.e., the polymorphic ancient Greek god Proteus, morphology), Ruminococcus obeum ("the egg," morphology), Saccharopolyspora rectivirgula ("the straight twig," morphology), and Vibrio nigripulchritudo ("the black beauty," colony color).

In contrast, in the following bacterial names the specific epithets do not fulfill the requirement of a nominative noun in apposition as explained above and therefore have to be grammatically changed. Non-Latinists can easily test the correctness of these names by introducing the word "called" (as shown above) between the genus name and the specific epithet. As none of them makes sense in the nominative apposition construction, we hereby correct these names to forms that are in agreement with Rule $12 \mathrm{c}$ as follows.

Aeromonas trota (Italian [!]: "the trout") is corrected to Aeromonas tructi (genitive noun: "of the trout," from Latin tructus, trout).

Catenococcus thiocyclus ("the sulfur cycle") is corrected to Catenococcus thiocycli (genitive noun: "of the sulfur cycle").

Clostridium laramie ("the city Laramie") is corrected to Clostridium laramiense (adjective: "of or from Laramie").

Corynebacterium vitarumen ("the rumen life") is corrected to Corynebacterium vitaeruminis (genitive noun: "from rumen life").

Globicatella sanguis ("the blood") is corrected to Globicatella sanguinis (genitive noun: "of the blood").

Haloanaerobium lacusroseus ("the pink lake") should be Haloanaerobium lacusrosei (genitive noun: "of or from a pink lake").

Helicobacter acinonyx ("the cheetah") is corrected to Helicobacter acinonychis (genitive noun: "of or from a cheetah").

Lactobacillus kefir ("the kefir") is corrected to Lactobacillus kefiri (genitive of kefirum, i.e., the latinized Turkish noun kefir: "of kefir").

Lactobacillus sake ("the sake") is corrected to Lactobacillus sakei (genitive of sakeum, i.e., the latinized Japanese noun sake: "of sake").

Lactobacillus sanfrancisco ("the city San Francisco") is corrected to Lactobacillus sanfranciscensis (adjective: "from San Francisco").

Nitrosococcus oceanus ("the ocean") is corrected to Nitrosococcus oceani (genitive noun: "of the ocean").

Pantoea (formerly Erwinia) ananas ("the pineapple," not "pathogenic for pineapple"!) is corrected to Pantoea ananatis (genitive of Latinized noun ananas: "of pineapple").

Photobacterium damsela ("the damselfish") is corrected to 
Photobacterium damselae (genitive of damsela, latinized English noun: "of damselfish").

Pseudomonas betle ("the betel plant") is corrected to Pseudomonas beteli (genitive of betelum, i.e., the latinized Malayan noun betel: "of betel").

Rickettsia canada ("the country Canada") is corrected to Rickettsia canadensis (adjective: "from Canada, Canadian").

Shewanella alga ("the alga") is corrected to Shewanella algae (genitive noun: "of an alga").

Sinorhizobium teranga ("the hospitality" in the West African Wolof language) is corrected to Sinorhizobium terangae (genitive of Latinized teranga, "of hospitality").

Streptococcus crista ("the crest") is corrected to Streptococcus cristatus (adjective: "ornamented by a crest").

Streptococcus rattus ("the mouse or rat") is corrected to Streptococcus ratti (genitive noun: "of the mouse or rat").

Streptococcus sanguis ("the blood") and its derivative Streptococcus parasanguis are corrected to Streptococcus sanguinis (genitive noun: "of the blood") and Streptococcus parasanguinis (genitive noun: "similar to the one of the blood"), respectively.

Streptomyces rangoon ("the city Rangoon") is corrected to Streptomyces rangoonensis (adjective: "of or from Rangoon"). Streptomyces scabies ("the potato scab") is corrected to Streptomyces scabiei (genitive noun: "of potato scab").

The specific epithet of Eubacterium tarantellus was intended as a masculine nominative Latin noun and was derived from the Italian feminine noun tarantella, used for a fast dance, because an infection of fish with this bacterium causes wild dance-like swarming behavior in the fish. The unnecessary formation of a masculine Latin noun should have been avoided, and tarantella should be introduced as a Neo-Latin word. We hereby correct the name to Eubacterium tarantellae (genitive noun: "of the tarantella").

Finally, there are a few specific epithets that on first viewing may appear to be nominative nouns but have been formed correctly as adjectives or genitive nouns; these constructions are Acholeplasma hippikon (Greek adjective: "pertaining to the horse"), Bergeyella zoohelcum (Latin plural genitive of Greek origin: "of animal wounds"), and Mycobacterium abscessus (Latin genitive noun of the 4th declension [also called the $u$ declension], genitive $-u s$ pronounced with a long $u$ : "of an abscess").

For microbiologists who are willing to acquire nomenclatural literacy or are about to describe or name prokaryotes we recommend reading references 4 and 5 .

\section{REFERENCES}

1. DSMZ-Deutsche Sammlung von Mikroorganismen und Zellkulturen GmbH 1996 (Dec.). Bacterial nomenclature up-to-date (Approved Lists, validation lists). DSMZ-Deutsche Sammlung von Mikroorganismen und Zellkulturen GmbH, Braunschweig, Germany.

2. Guralnik, D. B., and J. H. Friend (ed.). 1966. Webster's New World dictionary of the American language, college ed. The World Publishing Company, Cleveland, Ohio.

3. Lapage, S. P., P. H. A. Sneath, E. F. Lessel, V. B. D. Skerman, H. P. R. Seeliger, and W. A. Clark (ed.). 1992. International code of nomenclature of bacteria: bacteriological code, 1990 revision. American Society for Microbiology, Washington, D.C.

4. MacAdoo, T. O. 1993. Nomenclatural literacy, p. 339-358. In M. Goodfellow and A. G. O'Donnell (ed.), Handbook of new bacterial systematics. Academic Press, London, United Kingdom.

5. Trüper, H. G. 1996. Help! Latin! How to avoid the most common mistakes while giving Latin names to newly discovered prokaryotes. Microbiología (Sociedad Española de Microbiología) 12:473-475. 